\title{
Insect Meal as a Partial Replacement for Fish Meal in a Formulated Diet for Perch Perca fluviatilis
}

\author{
Sarvenaz Khalili Tilami ${ }^{1}$, Jan Turek ${ }^{2}$, Daniel Červený ${ }^{2}$, Pavel Lepič ${ }^{2}$, Pavel Kozák ${ }^{2}$, \\ Viktoriia Burkina ${ }^{2}$, Sidika Sakalli ${ }^{2}$, Aleš Tomčala ${ }^{1, *}$, Sabine Sampels ${ }^{1,3}$, Jan Mráz ${ }^{1}$
}

\begin{abstract}
${ }^{1}$ University of South Bohemia in České Budějovice, Faculty of Fisheries and Protection of Waters, Institute of Aquaculture and Protection of Waters, Husova tř. 458/102, 37005 České Budějovice, Czech Republic.

2University of South Bohemia in České Budějovice, Faculty of Fisheries and Protection of Waters, Research Institute of Fish Culture and Hydrobiology, Zátiší 728/II 38925 Vodňany, Czech Republic.

${ }^{3}$ Swedish University of Agricultural Sciences, Department of Molecular Sciences, Uppsala BioCenter, Box 7015, Uppsala, Sweden.
\end{abstract}

\section{Article History}

Received 05 May 2020

Accepted 30 October 2020

First Online 06 November 2020

\section{Corresponding Author}

Tel.: +420387774649

E-mail: a.tomcala@centrum.cz

\section{Keywords}

fishmeal alternatives

Perca fluviatilis

fatty acids analysis

Zophobas morio

Acheta domesticus

\begin{abstract}
The growing importance of aquaculture products for human health also raises the question of product sustainability and decreasing its costs. Insects are considered as novel feed ingredients and source of proteins. In this study, a twelve-week feeding trial with replacement of $25 \%$ fishmeal by a mixture of house cricket (Acheta domesticus) and superworm (Zophobas morio) in the fish feed was conducted with perch (Perca fluviatilis). There were no significant differences in this feeding trial, regarding survival, but decreased fish growth and increased feed conversion between the control and the experimental fed groups. Hepatic cytochrome P450 (CYP1A and CYP3A-like) activity and fatty acid (FA) composition were assessed in perch also. No significant effects were observed on cytochrome P450 activity associated with presence of toxic compounds in fish. Feeding with insect pellets resulted in significant increasing of linoleic FA and an increase of the total content of n-6 FA in fish fillets, compared to the fish fillets from control group. However, changes in FA composition were only minor and did not affect the nutritional value of the fish with insect-based diet for human consumption. Further evaluation should be conducted with different ratios or different insect species.
\end{abstract}

\section{Introduction}

Due to the increasing world population, there is also need for increased food production including animal proteins (Fawole et al., 2016). In comparison to other animal production sectors, aquaculture has recently grown very fast. For instance, the aquaculture production increased from $3.9 \%$ of total fish, crustacean and mussel production in 1970 to 33\% in 2005 (Gatlin et al., 2007) and even to 47\% in 2016 (FAO, 2018). The success of any aquaculture is based on many factors such as fish species, environmental conditions, nutrition and last but not the least the economy (Schnaittacher et al., 2005). The major operating expense in aquaculture is the cost of the feed (Brett, 1979), which is approximately $40-60 \%$ of the cost of production in aquaculture (Brown et al., 1996) and still increasing (FAO, 2018). Therefore, it is important to optimize the feeding strategy in a way that also reduces the costs of production (Schnaittacher, et al. 2005) and increases growth as well as feed conversion. Currently, there is an increased demand for high-quality feed ingredients for viable sources of protein and lipids. It is caused by several factors as drastic increase in the need for fish feed and stagnation of marine fish sources of protein, which are used in fishmeal (FM) (FAO, 2018). It is makes FM expensive and not sustainable. Feed costs are especially high for the culture of carnivorous fish, which require great amounts of FM in their diet (ManzanoAgugliaro et al., 2012). Currently, traditional oil feed ingredients has been partially replaced with alternative sources from terrestrial plants (Fawole et al., 2016; 
Gatlin et al., 2007; Medale et al., 2013; Quartararo et al., 1998). In addition, various animal protein sources have been considered as a replacement of FM (Bureau et al., 1999; Rawles et al., 2006). More recently, the use of insects as a protein source has been investigated (Henry et al., 2015; Ngoc et al., 2016; Nogales-Merida et al., 2018). Insects represent an attractive alternative to traditional sources of proteins due to their high feed conversion, quick growth, and their potential to feed on bio-waste (Collavo, 2005), which makes its production highly sustainable and cost-effective. In addition, they are a rich source of amino acids, lipids, vitamins and minerals (Finke, 2015; Nogales-Merida et al., 2018; van Huis, 2013). Since some insect species are consumed as part of the natural diet of fish (Howe, 2014), they might be an appropriate for partial replacement for FM. The amount of protein varies between $50-82 \%$ in different insect species, which reflects their good nutritional value (Nogales-Merida et al., 2018; Rumpold \& Schluter, 2013).

When choosing alternative feed components, including proteins, it is highly important to consider the needs of the fish species for which the feed is intended. In deciding which proteins and raw products are the most appropriate as feed ingredients for each species, priority must be given to the metabolic demands of the fish species. Factors, such as survival, growth and feed conversion need to be determined before a new feed component can be then considered adequate (Brown, et al. 1996).

Eurasian perch Perca fluviatilis is considered to be a popular game fish. However, there is generally little information regarding the feeding and dietary requirements of perch. Due to the absence of specific commercial feeds for perch on the market, formulated commercial diets for salmonids are used for perch (Brown, et al. 1996).

Eurasian perch is a carnivorous species with a high protein requirement. During their juvenile stage they consume mostly insects before starting fish based diet in the wild (Riddick, 2013). Therefore, fish feed containing insects is a promising candidate for partial FM replacement for perch. For instance, insects like black soldier fly Hermetica illucens (Bondari \& Sheppard, 1981), common housefly maggot Musca domestica (Ossey, 2012) , mealworm Tenebrio molitor ( $\mathrm{Ng}$ et al., 2001) and grasshopper Locusta migratoria (Johri, 2010) showed to be as sustainable alternatives to conventional animal proteins in fish nutrition, however, house cricket Acheta domesticus and superworm Zophobas moria insects have received less attention (Nogales-Merida et al., 2018)._Cricket and superworm have great potential for future use, since they are frequently cultivated and successfully used for pet nutrition (Finke, 2002; Nogales-Merida et al., 2018; Taufek et al., 2016). Furthermore, biomass production from insects is already established (Finke, 2002, 2015).

It should also be considered that insect biomass may contain potent bioactive compounds, which could be taken up by insects during growth via soil and water (Nogales-Merida et al., 2018). Therefore, it is important to examine potency of novel fish feed to affect the activity of fish metabolizing enzymes. Cytochrome P450 (CYP) enzymes are essential in the metabolism and clearance of endogenous compounds and xenobiotics including medicine compounds and feed components. CYP1A and CYP3A-like are well recognized biomarkers of presence of foreign compounds, which might be introduced thought the new diet (Burkina et al., 2018; Mraz et al., 2010). It was shown that inclusion of sesame in rainbow trout diet induced CYP1A activity (Trattner et al., 2008).

From a human nutritional point of view, a high content of long-chain n-3 fatty acids in fish are desired. Strong links between fish and seafood consumption and positive health effects, specially with a decreased risk of coronary heart and cardiovascular diseases, decreased inflammatory diseases, such as arthritis, and prevention of cancer have been earlier demonstrated (Lund, 2013; Russo, 2009; Simopoulos, 2002).

In the present study, a partial replacement of FM in perch diet was performed with using of whole insects composite. A mixture of house cricket Acheta domesticus and superworm Zophobas morio was used. Totally, one-quarter of FM was replaced by insects. Since FM comprises $40 \%$ of dry mass in control, the $1 / 4$ FM replacement by insects corresponds to $10 \%$ of the dry matter content, $5 \%$ per each insect species. The effects of experimental diet on perch survival, growth, feed conversion and the hepatosomatic index (HSI) as indicators for the well-being of the fish were assessed. Further, we studied fish hepatic CYP1A and CYP3A-like catalytic activity to investigate whether a new diet can modulate their activity. In addition, fatty acid (FA) composition, as an indicator of the nutritional value of fish for human consumption, was evaluated.

\section{Materials and Methods}

\section{Chemicals and Fish Feed Ingredients}

All chemical used were analytical grade with 9995\% purity and purchased from Sigma-Aldrich (Czech Republic). The ingredients of fish feed were a FM (protein (70-72\%), fat (max. 12\%), water (max. 10\%), salt (max. 4.5\%), ash (10-16\%), antioxidants (min 150 ppm ethoxyquin) ; Hanstholm Prime (FF Skagen), Denmark), wheat meal (Vesco, Veselí nad Lužnicí, Czech Republic), wheat gluten (Starch factory in Krnov - Krnovská škrobárna, Czech Republic), Achaeta domestica and Zophobas moria (local producer Vladimír Šefl, Bušanovice), salmon oil (Vfcux, Bioceval, Cuxhaven, Germany), Bolifor (Bioferm CZ, s. r.o., Brno, Czech Republic), and mineral mixtures (each $1,000 \mathrm{~g}$ of mineral premix of control diet: $162 \mathrm{mg} \mathrm{Fe;} 7 \mathrm{mg} \mathrm{Cu} ; 52 \mathrm{mg} \mathrm{Mn}$; $1 \mathrm{mg} \mathrm{Se} ; 88 \mathrm{mg} \mathrm{Zn;} 10 \mathrm{~g} \mathrm{~K}$ and insect containing diet: 129 mg Fe; 7 mg Cu; 49 mg Mn; 1 mg Se; 91 mg Zn; 8 g K). 


\section{Fish, Feeding Trial and Experimental Design}

Two isoenergetic and isoproteinic diets were formulated to provide both the protein and lipid requirements of the perch (for details see Table 1 and 2). The control diet (CONT) was based on FM only, and in the experimental diet (INS), 25\% of the original amount of FM was replaced with superworm and house cricket meals $(10 \%$ in total feed dry mass - $5 \%$ of each species). Insects were freeze-dried in liquid nitrogen and delivered to the feed production company (EXOT HOBBY s.r.o., Černá v Pošumaví) where the insects were milled and then processed into pelleted feed. From the fat content, $9 \%$ and $8.5 \%$ came from salmon oil made from fish by-products in the CONT and INS, respectively, while the rest originated from the other ingredients including the FM and insects. Threonine and methionine were added to both feeds to adjust for an adequate amino acid composition.

The feeding experiment was started after two weeks of fish acclimatization to the recirculation system and feeding conditions. Twelve-weeks feeding experiment was performed in a recirculation system at the experimental facility of the Faculty of Fisheries and Protection of Waters in Vodňany. Fish were handled according to national and institutional guidelines for the protection of human and animal welfare (facility unit is licensed No. 53100/2013-MZE-17214 according to the Czech National Directive Act No. 246/1992 Coll., on the Protection of Animals Against Cruelty).

A total of 1440 perch were randomly divided into two groups of 720 juveniles each (CONT and INS groups) and assigned to a dietary treatment with three replicates. In each replicate, 240 fish (mean weight of $23.1 \pm 0.6 \mathrm{~g}$ ) were held in $600 \mathrm{~L}$ round fibreglass tanks. The fish were fed continuously by an automatic feeder with a daily feed rate of $1.5 \%$ of the total weight of the stock. During the experiment, water parameters were checked twice a day (temp. $19.5 \pm 0.1{ }^{\circ} \mathrm{C}$, dissolved oxygen $9.2 \pm 0.6 \mathrm{mg} / \mathrm{L}$ ).

\section{Fish Sampling and Growth Performance}

The body weight and total length were recorded 5 times during the experiment at the beginning and then at a three-week interval using a total of 300 fish at each time point (150 per treatment, CONT and INS groups). Finally, the total fish stock of each tank was weighed at the end of the experiment after a $24 \mathrm{~h}$ starvation period. Survival was determined by observing the number of dead fish during the trial. Based on the measurements, the feed conversion ratio (FCR), specific growth rate (SGR), condition factor (CF), survival rate (SR) and hepatosomatic index (HSI) were calculated as follows:

Table 1. Ingredients composition in the two types of fish feed pellets

\begin{tabular}{|c|c|c|}
\hline Feed ingredients & CONT & INS \\
\hline Fishmeal a & 39 & 29 \\
\hline Wheat meal ${ }^{b}$ & 27 & 24 \\
\hline Wheat gluten ${ }^{c}$ & 20 & 22 \\
\hline Insects & - & 10 (5\% A.d., 5\% Z.m.) \\
\hline Salmon oil d & 9 & 8.5 \\
\hline Bolifore & 0.4 & 1 \\
\hline Brewer's yeast $^{f}$ & 3 & 3 \\
\hline Premix Vit & 0.35 & 0.35 \\
\hline Limestone & 0.3 & 0.75 \\
\hline
\end{tabular}

Table 2. Proximate composition of pellets

\begin{tabular}{lcc}
\hline Feed ingredients & CONT & INS \\
\hline Crude protein & 52.2 & 47.2 \\
Fat & 18.4 & 17.9 \\
Crude fibre & 2.45 & 3.21 \\
Ash & 7.07 & 7.09 \\
Mineral mixtures $^{\text {a }}$ & 2.2 & 3.53 \\
\hline
\end{tabular}

CONT - control feed; INS - feed 10\% house cricket and superworm. Data present as percentage of dry matter.

a Each 1000 g of mineral premix of CONT diet contained: 162 mg Fe; 7 mg Cu; 52 mg Mn; 1 mg Se; 88 mg Zn; 10 g K and INS diet contained: 129 mg Fe; 7 mg Cu; 49 mg Mn; 1 mg Se; 91 mg Zn; 8 g K. 


$$
\begin{gathered}
\mathrm{FCR}=\mathrm{F} /(\mathrm{Wt}-\mathrm{W} 0) . \\
\mathrm{SGR}=[(\ln \mathrm{Wt}-\ln \mathrm{W} 0) / \mathrm{t}] \times 100 \% \\
\mathrm{CF}=\mathrm{Wt} / \mathrm{T}^{3} \times 100 \% \\
\mathrm{SR}=[\mathrm{Nt} / \mathrm{NO}] \times 100 \% \\
\mathrm{HSI}=(\mathrm{WI} / \mathrm{TW}) \times 100 \%
\end{gathered}
$$

Where $\mathrm{Wt}=$ final weight of fish in $\mathrm{g}$; $\mathrm{WO}=$ initial weight of fish in g; $F=$ amount of dry feed fed in $g$; $t=$ time (days); $\mathrm{T}_{\mathrm{L}}=$ total length in $\mathrm{cm}$; $\mathrm{NO}=$ initial number of fish; $\mathrm{Nt}=$ final number of fish; $\mathrm{Wl}=$ weight of liver in $\mathrm{g} ; \mathrm{Tw}=$ total weight in $\mathrm{g}$.

At the beginning and at the end of the experiment, 10 fish from each group (START, CONT and INS) were sacrificed and filleted for analyses of FA content and composition. Fish total weight and liver weight were used for calculating the HSI. Liver samples were immediately frozen in liquid nitrogen and stored at -80 ${ }^{\circ} \mathrm{C}$ for further biochemical assays.

\section{Proximate Composition of Ingredients}

Crude protein, fat, fibre, ash and mineral composition analysis were provided by the State veterinary institute (Státní veterinární ústav Praha), Testing laboratory No. 1176 and AGRO-LA, spol.s.r.o.

\section{Amino Acid Composition Analyses}

Amino acid (AA) analyses were performed by AGRO-LA, spol.s.r.o. according to the standard method of commission regulation (EC) No 152 (2009).

\section{Lipid Content and Fatty Acid Composition Analysis}

Only triplicates of particular fish feed pellets for lipid and FA composition were processed, due to pellets homogeneity. Skinless fillets from 10 randomly chose fish originated from START (a group of fish at day 0 from experiment started), CON, and INS fish groups were used for lipid assessment.

The lipid extraction was based on the methods of Hara and Radin (1978). The raw lipid content was quantified gravimetrically. For FA profile analyses, methylation of total lipids was performed according to the methods of Appelqvist (1968). Methylated FA were analysed by gas chromatography (GC) (Trace Ultra FID; Thermo Scientific, Milan, Italy) using a BPX-70 50m fused silica capillary column (id. $0.22 \mathrm{~mm}, 0.25 \mu \mathrm{m}$ film thickness, SGE, USA). The peaks were identified by comparing sample retention times to retention times of the standard mixture GLC-68-A (Nu-Chek Prep, Elysian, USA).

\section{Microsomal Fraction Preparation and Protein Analysis}

Fish hepatic microsomes were prepared by differential centrifugation (Li et al., 2011). All steps of extraction were carried out on ice. Microsomal fractions were immediately frozen and stored at $-80^{\circ} \mathrm{C}$ for further analysis. The protein levels were estimated spectrophotometrically as described by Smith et al. (1985) using bovine serum albumin as the standard. The microsomes were diluted to obtain a protein concentration of $5 \mathrm{mg}$.

Determination of CYP1A and CYP3A-like enzyme activity in fish hepatic microsomes

The CYP1A and CYP3A-like enzyme activity were determined as ethoxyresorufin O-deethylase (EROD) and 7-benzyloxy-4-trifluoromethyl coumarin Odebenzylase (BFCOD) catalytic activity, respectively. EROD was measured as the rate in the formation of resorufin from 7-ethoxyresorufin (Kennedy \& Jones, 1994). The incubation mixtures contained $0.2 \mathrm{mg}$ microsomal protein in an incubation medium of $50 \mathrm{mM}$ potassium phosphate buffer $(\mathrm{pH} 7.4)$ with $1.0 \mathrm{mM}$ nicotinamide adenine dinucleotide phosphate (NADPH) and $2 \mu \mathrm{M}$ of 7-ethoxyresorufin. The catalytic activity of BFCOD was measured as the rate in the formation of 7 hydroxy-4-trifluoromethylcoumarin (HFC) from 7benzyloxy-4-trifluoromethylcoumarin (BFC) (Burkina et al., 2016). Briefly, the reaction incubations contain 0.2 $\mathrm{mg}$ of microsomal protein in an incubation medium of $50 \mathrm{mM}$ potassium phosphate buffer ( $\mathrm{pH} 7.4$ ) with 0.5 $\mathrm{mM} \mathrm{NADPH}$ and $12.5 \mu \mathrm{M}$ of BFC. A fluorescence detector (Infinite 200 - Photometer TECAN) was used for detection of resorufin (excitation/emission 544/590 $\mathrm{nm}$ ) and HFC (excitation/emission 410/538 nm). Enzymatic activities were expressed as pmol of resorufin or HFC formed per minute per $\mathrm{mg}$ of microsomal proteins (limits of detection were 2 and $1 \mathrm{pmol} / \mathrm{mL}$ for resorufin and $\mathrm{HFC}$, respectively).

\section{Statistical Analysis}

\section{T-test}

The statistical analysis was conducted using Statistica CZ 12 software package. The data are expressed as the mean \pm standard deviation. The significance levels were considered $\mathrm{P}<0.05$.

\section{Multivariate Statistic Analyses}

The obtained data of FA peak areas, growing parameters, and amino acids were statistically evaluated using ordination methods as follows: for all data - detrended correspondence analysis (DCA); for linear data - principal component analysis (PCA), redundancy analysis (RDA), Monte-Carlo permutation test (unrestricted permutations, $n=999)(P<0.05)$. The data was transformed by using the internal standard peak area of a particular sample followed by recalculation to the ratio of detected FAs and amino acids. For each, the transformed peak areas were calculated in the deconvoluted total cell and peak area. In the canonical analysis (RDA) the growing attributes stood as non-nominal ecological variables and the 
experimental feeding group as a categorical predictor. Monte-Carlo permutation test was used for statistical significance determination. Statistic software CANOCO 4.5 (Biometrics, Plant Research International, Wageningen UR, Netherlands) was used for the DCA, PCA, RDA, and Monte-Carlo permutation test analyses.

\section{Results}

\section{The Overall Composition of Insects}

The overall nutrient composition of the insects used for experimental fed is given in Table 3 and their FA composition in Table 4. Both insects possess a high proportion of water, which reaching almost three quarters in $A$. domestica. Comparison of these two insects revealed that $Z$. morio has a higher share of dry matter and house cricket has a higher presence of crude proteins. On the other hand, the superworm contains more crude fat.

In the extracted lipids from insects 19 FA in total were identified, form which ten FAs did not reach the $0.5 \%$ threshold. The four dominating FA are present in both insects: palmitic acid (C16:0), stearic acid (C18:0), oleic acid (C18:1 n-9), and linoleic acid (C18:2n-6).
In our study, the overall data multivariate analyses do not show significant differences between FA composition datasets $(\mathrm{P}=0.333)$ between studied insects. However, the t-tests show significant differences among six fatty acids (Table 4). Total polyunsaturated fatty acids (PUFA) were significantly higher and monounsaturated fatty acids (MUFA) were lower in the superworms compared to the house crickets. Total saturated fatty acids (SFA) showed similar contents in both insects. Total $n-6$ content was significantly higher in superworm compared to house crickets, whereas n-3 content was similar in both insects.

\section{The Overall Feed Composition}

The used feeds (CONT and INS) in this experiment were designed to be isoenergetic. Basic components proportion of pellets dry matter is present in Table 2. The dry matter of control and insect containing pellets consist of $52.2 \%$ and $47.2 \%$ crude protein, $18.4 \%$ and $17.9 \%$ crude fat, and $7 \%$ and $7 \%$ ash, respectively (Table 2).

Fish pellets AAs proximate composition is presented in Table 5. In total, 18 AAs were detected and

Table 3. Proximate composition of insects

\begin{tabular}{lcc}
\hline & House cricket & Superworm \\
Dry matter & 32.3 & 43.8 \\
Water & 67.7 & 56.2 \\
Total carbohydrate & 4.1 & 4.7 \\
Crude fat & 4.6 & 18.3 \\
Crude protein & 21.7 & 19 \\
Ash & 1.9 & 1.8 \\
Energy value (kJ/100g) & 606 & 1080 \\
\hline
\end{tabular}

House cricket (Acheta domesticus) and superworm (Zophobas morio). Insects were analysed by accredited laboratory (Státní veterinární ústav Praha, Testing laboratory No. 1176). Data are presented as percent of total diet composition (except for energy value).

Table 4. Fatty acid composition (\%, higher than $0.5 \%)$ of insects

\begin{tabular}{|c|c|c|}
\hline & House cricket & Superworm \\
\hline C14:0 & $0.68 \pm 0.06^{a}$ & $1.09 \pm 0.06^{b}$ \\
\hline $\mathrm{C} 16: 0$ & $24.1 \pm 0.61^{\mathrm{a}}$ & $28.4 \pm 0.00^{b}$ \\
\hline C16:1trans & $0.48 \pm 0.03^{a}$ & $1.52 \pm 0.20^{b}$ \\
\hline C16:1 & $0.92 \pm 0.08$ & $0.91 \pm 0.06$ \\
\hline C18:0 & $9.78 \pm 0.23^{a}$ & $7.86 \pm 0.15^{b}$ \\
\hline C18:1n-9 & $27.9 \pm 1.17^{a}$ & $38.7 \pm 0.29^{b}$ \\
\hline C18:1n-7 & $0.54 \pm 0.03$ & $0.73 \pm 0.05$ \\
\hline$C 18: 2 n-6$ & $33.5 \pm 0.12^{\mathrm{a}}$ & $18.8 \pm 0.17^{b}$ \\
\hline$C 18: 3 n-3$ & $1.19 \pm 0.07$ & $1.15 \pm 0.05$ \\
\hline SFA & $34.8 \pm 0.91$ & $37.5 \pm 0.12$ \\
\hline MUFA & $30.1 \pm 1.12^{\mathrm{a}}$ & $42.2 \pm 0.37^{b}$ \\
\hline PUFA & $35.2 \pm 0.21^{\mathrm{a}}$ & $20.3 \pm 0.25^{b}$ \\
\hline$n-3$ & $1.17 \pm 0.32$ & $1.15 \pm 0.09$ \\
\hline$n-6$ & $33.6 \pm 0.15^{\mathrm{a}}$ & $18.8 \pm 0.16^{b}$ \\
\hline
\end{tabular}


4 of them were below $1 \%$. All ten essential AAs were present in both types of feed pellets with a comparable composition (Table 5). The most abundant AA was glutamate, it was slightly higher in the control pellets. No significant differences were observed between AAs in control and insect containing pellets $(P=0.338)$.

CONT and INS containing pellets FA composition is presented in Table 6. A total of 22 FAs were detected and 8 of them were below $0.5 \%$. The most abundant FAs were C18:1 n-9, C18:2 n-6, and C 16:0 in both pellet types. They were constituting together almost $70 \%$ of all FAs in pellets. The ratio of $n-3$ to $n-6$ FAs is significantly higher in CONT pellets $(0.71)$ in comparison to INS pellets (0.61).

\section{Fish Growth Parameters, Survival, Fatty Acid Composition and CYPs Activity}

Survival rate, initial and final weight and length, and the fish performance factors are presented in Table 7. The average weight gain, final weight and SGR of the fish fed by INS pellets were significantly lower, while FCR was significantly higher compared to the CONT group $(P \leq 0.05)$. The CF and HSI did not significantly differ between groups (T-test).

The fat content and FA profile in the fish fillets from the present study are shown in Table 8. The most abundant FA was C22:6 n-3, followed by C16:0, C18:1 n9 and C18:2 n- 6 with more than 10\% of presented FA in fillets from both CONT and INS fish. Partial multivariate statistic analysis of detected FAs and their content did not differ significantly between the samples from CONT and INS fish $(P=0.404)$. Fillet FA content was similar in both feeding groups and did not change throughout the experiment.

Modulation of piscine CYPs activity became a central focus in aquatic risk evaluation. CYPs can be induced or inhibited in the presence of numerous medicines and other environmental contaminants (Burkina et al., 2018). In the current study, fish hepatic CYP1A and CYP3A-like enzymatic activity of INT group remained to be similar to levels of fish from CONT group ( $P>0.05)$ (Figure 1).

\section{Correlations Between Two Diets and Studied Fish Parameters}

The correlation between two diets and studied biomarkers are presented in Figure 2. The analyses revealed significant differences between the control and insect group $(P=0.001)$. The biplot represents a $2 \mathrm{D}$ model of spatial data distribution explaining the $95.5 \%$ variability of the dataset in the $\mathrm{X}$-axis and $4.4 \%$ in the $\mathrm{Y}$ axis. The position of triangles representing the experimental groups and points to the finding that significant differences are small because position on $\mathrm{X}$ axis of diagram explaining $95.5 \%$ of the dataset variability. The main fish parameters responsible for data segregation are attributes derivate from the differences between initial and final weight of CONT and INS fish. Notice the direction and length of the arrows representing FCR and SGR (Figure 2). FCR have positive correlation with INS group contrary, SGR with CON group.

\section{Discussion}

For the first time, we are reporting whether the $25 \%$ replacement of FM by insects (of house cricket and superworm in equal mixture) in the fish feed for perch could affected fish survival, growth parameters, HSI, and FA composition and if introduced to fish feed insect ingredient has xenobiotic nature, which causing alteration in perch enzyme activity. Moreover, nutrients proximate composition and FA profile of used insect $Z$. morio and $A$. domestica were characterized. These two insect species were chosen due to their easier and standardised breeding, and for being an excellent source of $A A, F A$, and vitamins. For instance, from the earlier evaluated insect species only superworms and crickets contained sufficient vitamin A activity for most insectivorous species (Finke, 2015).

\section{The Overall Composition of Insects}

Previous reports of $A$. domestica and Z.morio nutritional composition of insect water content is ranged between $63-73 \%$ and $57-62 \%$, crude fat 3.3-6\% and $14-17.5 \%$ for house cricket and superworm respectively (Barker et al., 1998; Finke, 2002, 2015). Insects which were used in present study showed similar nutritional composition ranges to mentioned labours (Table 3.).

The four dominating FA were detected in examined insect both insects (C16:0, C18:0, C18:1 n-9, C18:2 n-6). A very similar result was reported earlier (Finke, 2002, 2015; Leung et al., 2012). However, it should be noted, that generally, the occurrence of FAs in the insect is reflecting FAs composition in the insects feed (NogalesMerida et al., 2018). Therefore, comparison of insect FA profile in the present study with other reports is not relevant.

\section{The Overall Feed Composition}

There are few factors which are crucial for optimization of the fish growth are the ratio of fat and protein in the feed (Brown et al., 1996; Xu et al., 2001), the balance of dietary PUFA and SFA and the ratio of $n$ 3/n-6 FA (Blanchard et al., 2008). The used feeds (CONT and INS) in this experiment were designed to be isoenergetic.

The ratio of protein to fat in both feeds in the present study is similar to the ratio used by previous nutritional studies on $P$. fluviatilis evaluating different fat sources (fish/plants) (Blanchard et al., 2008)(Blanchard, et al. 2008) (from nature/ from fish feed) (Jankowska et al., 2010)._Crude fibre as well as 
Table 5. Amino acid composition of pellets

\begin{tabular}{|c|c|c|}
\hline & CONT & INS \\
\hline \multicolumn{3}{|c|}{ Essential amino acids } \\
\hline Histidine & 0.77 & 0.75 \\
\hline Isolucine & 1.59 & 1.44 \\
\hline Lucine & 3.03 & 3.02 \\
\hline Phenylalanine & 1.69 & 1.61 \\
\hline Valine & 1.82 & 1.73 \\
\hline Lysine & 2.81 & 3.08 \\
\hline Methionine & 0.66 & 0.69 \\
\hline Cystine & 0.42 & 0.42 \\
\hline Threonine & 1.62 & 1.79 \\
\hline Tryptophan & 0.79 & 0.76 \\
\hline Arginine & 1.91 & 1.77 \\
\hline \multicolumn{3}{|c|}{ Non-essential amino acids } \\
\hline Aspartate & 3.06 & 2.86 \\
\hline Serine & 1.97 & 1.79 \\
\hline Glutamate & 12.5 & 11.6 \\
\hline Glycine & 2.85 & 2.60 \\
\hline Alanine & 2.90 & 2.74 \\
\hline Tyrosine & 1.28 & 1.24 \\
\hline Proline & 3.17 & 3.02 \\
\hline
\end{tabular}

CONT - control feed; INS - feed 10\% house cricket and superworm. Data are expressed as percentage of dry matter.

Table 6. Fatty acid composition of pellets (\%, higher than $0.5 \%)$

\begin{tabular}{lcc}
\hline & CONT & INS \\
\hline Fat content & $18.4 \pm 0.64$ & $18.0 \pm 0.40$ \\
C14:0 & $2.83 \pm 0.02^{\mathrm{a}}$ & $2.55 \pm 0.04^{\mathrm{b}}$ \\
C16:0 & $13.2 \pm 0.14^{\mathrm{a}}$ & $14.8 \pm 0.37^{\mathrm{b}}$ \\
C16:1 & $3.15 \pm 0.03^{\mathrm{a}}$ & $2.80 \pm 0.02^{\mathrm{b}}$ \\
C18:0 & $2.75 \pm 0.04^{\mathrm{a}}$ & $3.20 \pm 0.07^{\mathrm{b}}$ \\
C18:1n-9 & $36.2 \pm 0.27$ & $35.3 \pm 0.28$ \\
C18:1n-7 & $3.04 \pm 0.09^{\mathrm{a}}$ & $2.64 \pm 0.02^{\mathrm{b}}$ \\
C18:2n-6 & $16.6 \pm 0.03^{\mathrm{a}}$ & $17.0 \pm 0.12^{\mathrm{b}}$ \\
C18:3n-3 & $4.94 \pm 0.10^{\mathrm{a}}$ & $4.53 \pm 0.04^{\mathrm{b}}$ \\
C22:1n-9 & $2.30 \pm 1.68$ & $3.00 \pm 0.01$ \\
C20:5n-3 & $2.24 \pm 1.15$ & $2.45 \pm 0.01$ \\
C24:1 & $3.99 \pm 0.09^{\mathrm{a}}$ & $3.25 \pm 0.04^{\mathrm{b}}$ \\
C22:5n-3 & $0.56 \pm 0.01^{\mathrm{a}}$ & $0.49 \pm 0.01^{\mathrm{b}}$ \\
C22:6n-3 & $1.07 \pm 0.02$ & $1.02 \pm 0.17$ \\
\hline SFA & $5.77 \pm 0.17^{\mathrm{a}}$ & $4.73 \pm 0.00^{\mathrm{b}}$ \\
MUFA & $19.2 \pm 0.29^{\mathrm{a}}$ & $20.9 \pm 0.37^{\mathrm{b}}$ \\
PUFA & $47.7 \pm 0.15$ & $47.0 \pm 0.32$ \\
n-3 & $33.1 \pm 0.44$ & $32.1 \pm 0.05$ \\
n-6 & $16.2 \pm 0.32^{\mathrm{a}}$ & $13.9 \pm 0.08^{\mathrm{b}}$ \\
n-3/n-6 & $22.7 \pm 0.29^{\mathrm{a}}$ & $22.9 \pm 0.13^{\mathrm{b}}$ \\
\hline CONT - a & $0.71 \pm 0.01^{\mathrm{a}}$ & $0.61 \pm 0.02^{\mathrm{b}}$ \\
\hline
\end{tabular}

CONT - control feed; INS - feed 10\% house cricket and superworm. Data are present as mean \pm standard deviation. Different small letters indicate significant differences between the CONT and INS pellets $(p \leq 0.05)$. SFA - saturated fatty acids, MUFA - monounsaturated fatty acids, PUFA polyunsaturated fatty acids.

Table 7. Performance factors for fish

\begin{tabular}{lcc}
\hline & CONT & INS \\
\hline Survival, \% & $94.0 \pm 4.0$ & $94.6 \pm 1.90$ \\
Initial weight, g & $23.4 \pm 0.10$ & $22.8 \pm 0.90$ \\
Final weight, g & $56.9 \pm 0.70^{\mathrm{a}}$ & $48.6 \pm 2.10^{\mathrm{b}}$ \\
Weight gain, g & $33.5 \pm 0.61^{\mathrm{a}}$ & $25.7 \pm 2.23^{\mathrm{b}}$ \\
FCR, \% & $1.44 \pm 0.08^{\mathrm{a}}$ & $1.75 \pm 0.15^{\mathrm{b}}$ \\
SGR, \%/day & $1.06 \pm 0.01^{\mathrm{a}}$ & $0.90 \pm 0.07^{\mathrm{b}}$ \\
CF, \% & $1.49 \pm 0.11$ & $1.43 \pm 0.13$ \\
HSI, \% $(\mathrm{n}=10)$ & $3.60 \pm 0.90$ & $3.80 \pm 0.60$ \\
\hline
\end{tabular}

CONT - control feed; INS - feed $10 \%$ house cricket and superworm .Data are presented as the mean \pm standard deviation, $n=150$. Means with different superscripts are significantly different $(P<0.05)$ compared to control group. HSI was calculated for 10 randomly chosen fish in each group. Different superscripts indicate significant differences between the groups $(p \leq 0.05)$. FCR - feed conversion ratio, SGR - specific growth rate, CF condition factor, $\mathrm{HSI}$ - hepatosomatic index. 
Table 8. Total identified fatty acids (\%) in skinless fillet of perch (higher than $0.5 \%$ )

\begin{tabular}{lccc}
\hline & START & CONT final & INS final \\
\hline Fat content & $1.53 \pm 1.30$ & $1.08 \pm 0.32$ & $1.21 \pm 0.25$ \\
C14:0 & $0.78 \pm 0.10$ & $1.23 \pm 0.40$ & $1.14 \pm 0.27$ \\
C16:1trans & $22.1 \pm 1.02$ & $22.6 \pm 1.26$ & $23.1 \pm 0.79$ \\
C16:1 & $1.15 \pm 0.23$ & $1.16 \pm 0.16$ & $1.28 \pm 0.17$ \\
C18:0 & $2.30 \pm 0.49$ & $3.04 \pm 1.45$ & $3.00 \pm 1.19$ \\
C18:1n-9 & $3.68 \pm 0.32$ & $3.82 \pm 0.66$ & $4.10 \pm 0.47$ \\
C18:1n-7 & $15.1 \pm 1.88$ & $18.4 \pm 4.64$ & $18.3 \pm 3.08$ \\
C18:1n-5 & $2.23 \pm 0.14$ & $2.28 \pm 0.22$ & $2.18 \pm 0.10$ \\
C18:2n-6 & $0.63 \pm 0.03$ & $0.47 \pm 0.12$ & $0.45 \pm 0.08$ \\
C18:3n-3 & $9.34 \pm 1.15$ & $9.45 \pm 0.85^{\mathrm{a}}$ & $10.9 \pm 0.70^{\mathrm{b}}$ \\
C20:1n-9 & $1.24 \pm 0.14$ & $1.82 \pm 0.28$ & $1.78 \pm 0.21$ \\
C20:4n-6 & $1.25 \pm 0.16$ & $1.52 \pm 0.18^{\mathrm{a}}$ & $1.30 \pm 0.24^{\mathrm{b}}$ \\
C20:5n-3 & $0.99 \pm 0.14$ & $0.81 \pm 0.18$ & $0.71 \pm 0.10$ \\
C22:5n-3 & $3.46 \pm 0.74$ & $4.66 \pm 0.6$ & $4.13 \pm 0.64$ \\
C22:6n-3 & $1.37 \pm 0.25$ & $1.73 \pm 0.37$ & $1.57 \pm 0.21$ \\
\hline SFA & $34.3 \pm 3.00$ & $25.3 \pm 5.17$ & $24.6 \pm 4.20$ \\
MUFA & $26.8 \pm 1.53$ & $27.9 \pm 1.47$ & $28.6 \pm 0.96$ \\
PUFA & $23.2 \pm 3.00$ & $27.93 \pm 6.34$ & $27.5 \pm 4.55$ \\
n-3 & $50.8 \pm 5.46$ & $44.21 \pm 5.15$ & $43.9 \pm 4.03$ \\
n-6 & $40.5 \pm 4.17$ & $33.9 \pm 5.76$ & $32.4 \pm 4.56$ \\
n-3/n-6 & $10.3 \pm 1.29$ & $10.3 \pm 0.75^{\mathrm{a}}$ & $11.6 \pm 0.68^{\mathrm{b}}$ \\
\hline Te & $3.91 \pm 0.31$ & $3.29 \pm 0.05$ & $2.79 \pm 0.08$ \\
\hline
\end{tabular}

The beginning (START) and at the end of the experiment fed with control (CONT) or experimental diet containing $10 \%$ house cricket and superworm (INS). Data are present as mean \pm standard deviation, $n=10$. Different superscripts indicate significant differences between the groups ( $p \leq 0.05)$. SFA - saturated fatty acids, MUFA - monounsaturated fatty acids, PUFA - polyunsaturated fatty acids.

Figure 1. 7-ethoxyresorufin-O-deethylation (EROD, A) and benzyloxy-4-trifluoromethylcoumarin-O-debenzyloxylation (BFCOD, B) activity in hepatic microsomes from perch after 12 weeks of feeding trial. Enzyme activity is shown as pmol per min per mg of microsomal protein (mean \pm standard error, $n=10$ in each group).

A.

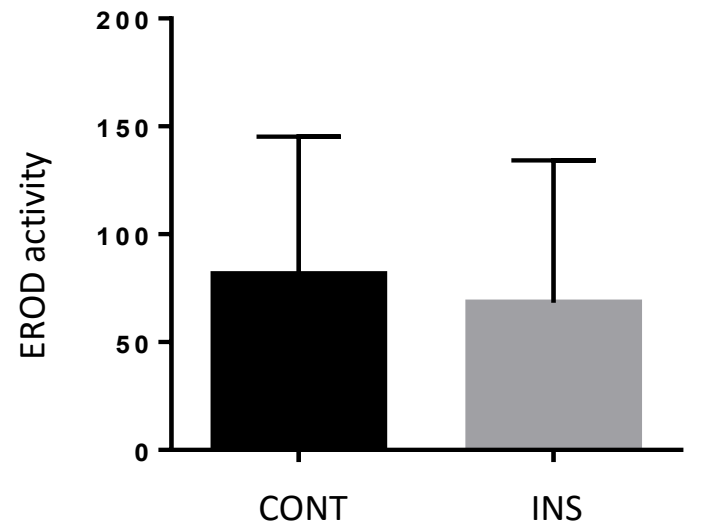

B.

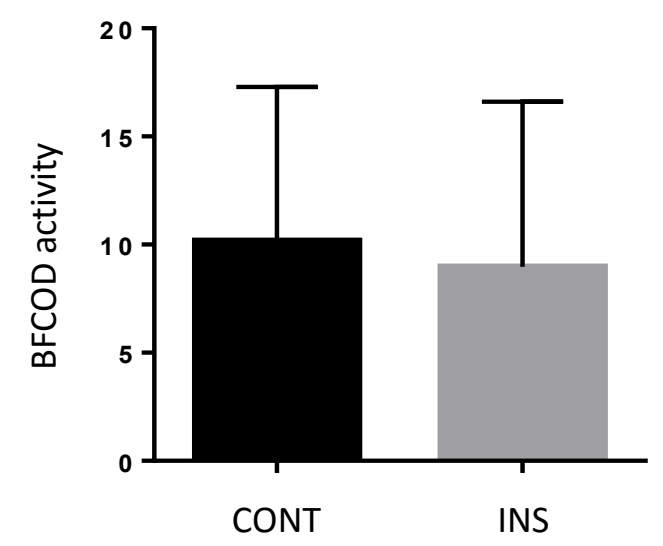




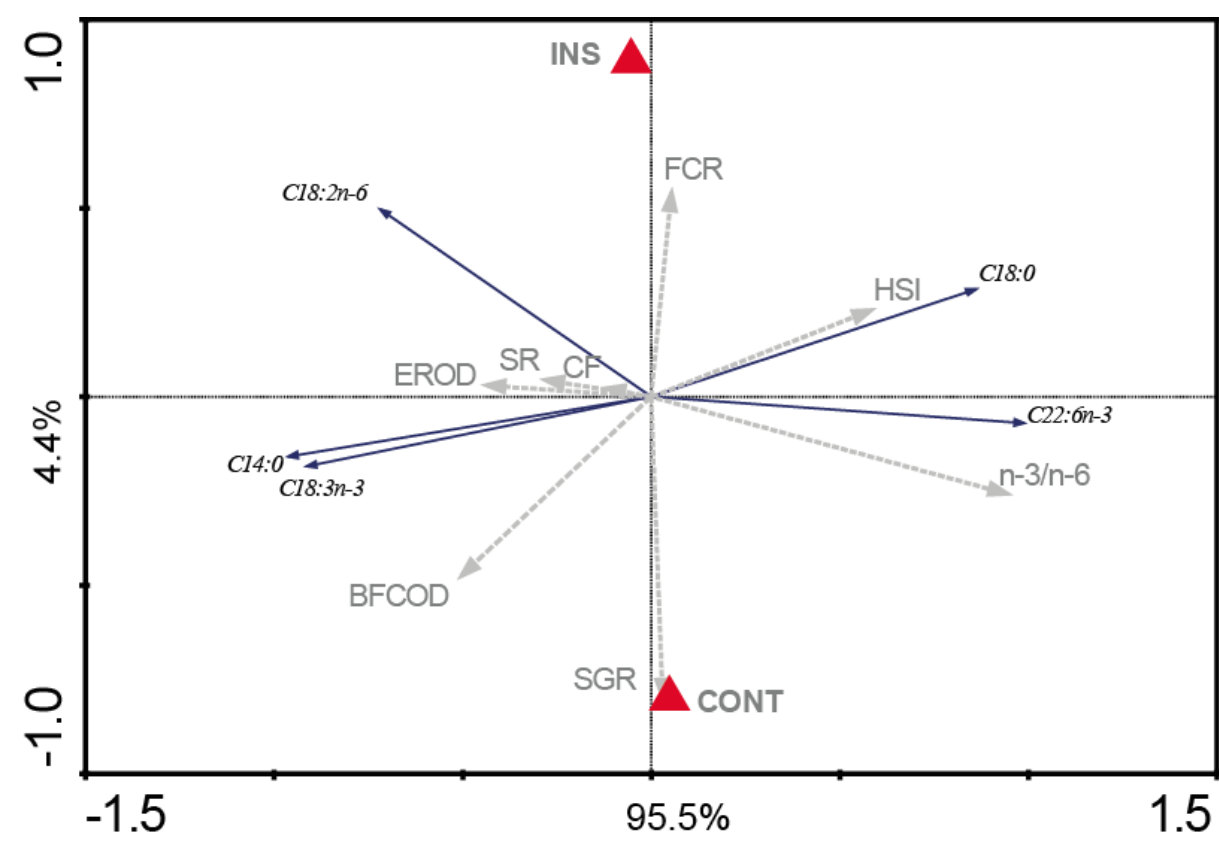

Figure 2. RDA ordination biplot ( $1^{\text {st }}$ and $2^{\text {nd }}$ ordination axes) showing the relationships between the studied groups of fish. Red triangles - treated as categorical environmental variable. Gray arrows - quantitative environmental variables (FCR - feed conversion ratio, SGR -specific growth rate, CF - condition factor, SR - survival rate, HSI - hepatosomatic index, EROD - level of CYP1A activity, BFCOD - level of CYP3A activity) and blue arrows - response variables (blue darts - occurrence of fatty acids and amino acids). The angles among individual arrows show their mutual inter correlations, while lengths of the arrows show their relative strengths in the ordination. See Table 6 and 7 and Figure 1 for related statistical values.

minerals was slightly higher in the insect containing pellets which could be caused by the chitinous exoskeleton of insects (Taufek et al., 2016).

In our study it the ratio of $n-3$ to $n-6$ FAs significantly higher in CONT pellets $(0.71)$ than in INS pellets (0.61). The reason is most probably only a trace level of $n-3$ unsaturated fatty acids longer than 18 carbons in both used insect species in comparison with a FM known to be rich in n-3 PUFAs.

The fish feed pellets with the replacement of $25 \%$ FM by insects were assumed as an appropriate replacement for control feed pellets and the differences in the mentioned quality attributes could be considered as negligible.

\section{Fish Growth Parameters, Survival, Fatty Acid Composition and CYPs Activity}

T-test of fish well being parameters revealed significant differences between the CONT and INS fish group. The average weight gain, final weight and SGR of the fish fed by INS pellets were lower, while FCR was higher (Table 7.). Generally, the lower growth parameters in the experimental group indicate lower nutritional value and digestibility of the feed. Since there were no differences between nutritional proximate composition, FA and AA profiles between CONT and INS pellets, the lower nutritional value of INS pellets could be excluded. Blanchard et al. (2008) showed that different $n-3 / n-6$ ratio has no significant effect on FCR and SCR. The lower growth parameters can be affected by sensory factors of INS pellets, which caused lower feed consumption by perch $(P=0.06)$. We hypthetized that the lower palatability of INS feed could be caused by unpalatable flavour, bitterness, sourness or odour. Slower fish growth as a result of low feed consumption could be also caused presence of oxidised fat (Finke, 2002) or by chitin (Taufek et al., 2016). Also, the process of feed preparation is very important since meal processing steps such freezing or drying affect the quality and palatability of the insects present in the feed. An example is the Maillard reaction, which can occurred during the drying process (Nogales-Merida et al., 2018). Similar results of a lower fish performance with partial substitution of $10 \%$ FM by dried larvae of the soldier fly (Hermetia illucens L) were found in channel catfish (Ictalurus punctatus) when reared during a 15-week period in cages. However, catfish reared in culture tanks on the same diet, showed a not significant decrease in growth, indicating that besides insect based feed, the rearing system also had some influence on fish performance (Bondari \& Sheppard, 1981). In contrast to our results, channel catfish which was fed partially or fully with soldier fly larvae showed the same performance in total weight and length compared to the control group (Bondari \& Sheppard, 1981). This indicates that insect species and replacement proportion have different effects on fish performance indexes. Also, the proportion of replacement needs a thorough evaluation. For instance, replacement of crude energy in rainbow trout (Oncorhynchus mykkis) diet by $25 \%$ and $100 \%$ of $Z$. morio or $A$. domesticus or their combination tend to correlate with increasing FCR and decreasing $n-3 / n-6$ 
ratio (Turek et al., 2020). Other example could be inclusion of different proportion of superworm $(0,25$, 50,75 , and $100 \%$ ) in fish feed for juvenile Nile tilapia (Oreochromis niloticus) showed higher weight gain and SGR for fish fed with diets of 25 and $50 \%$ superworm meal compared to fish fed with a higher degree of replacement. In the group supplemented with $100 \%$ superworm in fish feed, a decreased fish growth performance compared to the groups fed with lower ratios was observed (Jabir et al., 2012). These results indicate that there is an upper level for the inclusion of insects as a protein source in fish feeds. In our study, insect inclusion resulted in slight decreasing of fish growth rate, which shows that either the chosen insect mixture was not the most suitable or that the proportion was already too high. However, SGR values in previous work dealing with other perch species, $P$. fluviatilis, feeding experiments (Blanchard et al., 2008; Xu et al., 2001) were recorded from 0.43 to 1.19 . The comparison with our results revealed that the differences in SGR between CONT and INS groups are significant but from a more general point of view only negligible.

Final FA composition of the fish fillet was only affected to a minor extent and FA profile of perch was similar as shown earlier (Blanchard et al., 2008; Jankowska et al., 2010) with only one exception. The C18:2 n- 6 reached around 10\% of total FAs in both groups (CONT and INS). The results from previous studies were lower, $4.9 \%$ and $3.75 \%$ in reared and wild $P$. fluviatilis, respectively (Jankowska et al., 2010). The reason for significantly higher values of $18: 2$ n- 6 in both, CONT and INS, fish groups could be in the source of fat in FM. The slightly higher amount of C18:2 n-6 in the INS fish, compared to the CONT fish, is might be due to higher content of this FA in crickets and superworms and subsequently in the experimental diet and mirroring the FA composition of the feeds. Similar effects have been seen earlier, for instance, fish feed containing sunflower oil, rich for C18:2 n-6, caused a similarly high level of C18:2 n-6 in the perch fillets (Blanchard et al., 2008). Interestingly, C20:1 n-9 was decreased in the INS fish fillets in comparison to CONT, even though the INS pellets contain a higher amount of this FA. Feeding with INS pellets also resulted in increased C20:4 n-6, C22:4 n6 , and decreased $\mathrm{C} 20: 5 \mathrm{n}-3$, and $\mathrm{C} 22: 6 \mathrm{n}-3$ (Table 8), which subsequently leads to an increased total $n-6$ compared to the CONT group and a decrease in the content of the long-chain n-3 FA C22:6n-3, an important feature of fish meat from a human nutritional point of view. This phenomenon was also observed by Turek et al. (2020) in dietary experiments with rainbow trout. In present study, n-3/n-6 ratio was 3.3 and 2.8 for CON and INS, respectively. Since a part of the wild juvenile perch feed in nature are insects (Thorpe, 1977), our results follow published data where the $n-3 / n-6$ ratio can reach 4.6 in cultured and 2.2 in wild perch (Jankowska et al., 2010). Therefore, the results of this study indicate that even though the $n-3 / n-6$ ratio between the CONT and INS fish groups is significantly different, this difference is within the natural borders. Hence, we can assume that the chosen proportion and mixture of insects did not negatively affecting the FAs composition of perch fillets, even if the insects lead to a slight decrease of the nutritional value of the fish for consumers.

In the current study, fish hepatic CYP1A and CYP3Alike enzymatic activity of INT group remained to be similar to levels of fish from CONT group $(P>0.05)$ (Figure 1). This suggests that INS diet does not contain toxic compounds (Burkina et al., 2018) and can be considered as safe and more sustainable alternative diet for perch. However, use of insects cultivated on by-products from agriculture in fish feed may exert a risk on fish health and finally consumer, because of unknown load of harmful chemicals.

\section{Conclusion}

The presented work clearly shows the potential of insects (house cricket - Acheta domesticus and superworm - Zophobas morio) as a nutritionally appropriate replacement (25\%) for FM in fish feeds, even if some growth parameters were affected in fish with such FM replacement. It should be highlighted that fish feed has to be specifically designed for each species to meet its nutritional demands. Evaluation of other combinations of insect species and different proportions in feed for perch should be investigated to find the best replacement resulting in similar or improved fish growth parameters.

\section{Acknowledgements}

This research was supported by the Ministry of Education, Youth and Sports of the Czech Republic through projects "CENAKVA" LM2018099 and "CENAKAVA Center Development": CZ.1.05/2.1.00/19.0380, Reproductive and Genetic Procedures for Preserving Fish Biodiversity and Aquaculture (CZ.02.1.01/0.0/0.0/16_025/0007370) and by the NAZV projects: QJ1510119, QK1810296. The authors declare no conflicts of interest.

\section{References}

Appelqvist, L. A. (1968). Rapid methods of lipid extraction and fatty acid methyl ester preparation for seed and leaf tissue with special remarks on preventing accumulation of lipid contaminants. Arkiv for Kemi, 28(6), 551-+. <Go to $|S|>: / /$ WOS:A1968B321100003

Barker, D., Fitzpatrick, M. P., \& Dierenfeld, E. S. (1998). Nutrient composition of selected whole invertebrates. Zoo Biology, 17(2), 123-134. https://doi.org/10.1002/(sici)1098-2361

Blanchard, G., Makombu, J. G., \& Kestemont, P. (2008). Influence of different dietary 18:3n-3/18:2n-6 ratio on growth performance, fatty acid composition and hepatic ultrastructure in Eurasian perch, Perca fluviatilis. Aquaculture, 284(1-4), 144-150. https://doi.org/10.1016/j.aquaculture.2008.07.011 
Bondari, K., \& Sheppard, D. C. (1981). Soldier fly larvae as feed in commercial fish production. Aquaculture, 24(1-2), 103-109. https://doi.org/10.1016/0044-8486(81)900478

Brett, J. (1979). Environmental factors and growth. In W. Hoar, D. Randall, \& J. Brett (Eds.), Bioenergetics and Growth. Fish Physiology. (pp. 599-675). Academic Press.

Brown, P. B., Dabrowski, K., \& Garling, D. L. (1996). Nutrition and feeding of yellow perch (Perca flavescens). Journal of Applied Ichthyology, 12(3-4), 171-174. https://doi.org/10.1111/j.1439-0426.1996.tb00084.x

Bureau, D. P., Harris, A. M., \& Cho, C. Y. (1999). Apparent digestibility of rendered animal protein ingredients for rainbow trout (Oncorhynchus mykiss). Aquaculture, 180(3-4), 345-358. https://doi.org/10.1016/s00448486(99)00210-0

Burkina, V., Sakalli, S., Pilipenko, N., Zlabek, V., \& Zamaratskaia, G. (2018). Effect of human pharmaceuticals common to aquatic environments on hepatic CYP1A and CYP3A-like activities in rainbow trout (Oncorhynchus mykiss): An in vitro study. Chemosphere, 205, 380-386. https://doi.org/10.1016/j.chemosphere.2018.04.080

Burkina, V., Zlabek, V., Halsne, R., Ropstad, E., \& Zamaratskaia, G. (2016). In vitro effects of the citrus flavonoids diosmin, naringenin and naringin on the hepatic drugmetabolizing CYP3A enzyme in human, pig, mouse and fish. Biochemical Pharmacology, 110, 109-116. https://doi.org/10.1016/j.bcp.2016.04.011

Collavo, A., Glew, R.H., Huang, Y.S., Chuang, L.T, Bosse, R., Paoletti, M.G. (2005). House cricket small-scale farming. In M. G. Paoletti (Ed.), Ecological Implications of Minilivestock: Potential of Insects, Rodents, Frogs and Snails. (pp. 519-544). Science Publishers.

FAO. (2018). The State of World Fisheries and Aquaculture 2018 - Meeting the sustainable development goals. Rome.

Fawole, F. J., Sahu, N. P., Jain, K. K., Gupta, S., Shamna, N., Phulia, V., \& Prabu, D. L. (2016). Nutritional evaluation of protein isolate from rubber seed in the diet of Labeo rohita: Effects on growth performance, nutrient utilization, whole body composition and metabolic enzymes activity. Animal Feed Science and Technology, 219, https://doi.org/10.1016/j.anifeedsci.2016.06.014

Finke, M. D. (2002). Complete nutrient composition of commercially raised invertebrates used as food for insectivores. Zoo Biology, 21(3), 269-285. https://doi.org/10.1002/zoo.10031

Finke, M. D. (2015). Complete nutrient content of four species of commercially available feeder insects fed enhanced diets during growth. Zoo Biology, 34(6), 554-564. https://doi.org/10.1002/zoo.21246

Gatlin, D. M., Barrows, F. T., Brown, P., Dabrowski, K., Gaylord, T. G., Hardy, R. W., Herman, E., Hu, G. S., Krogdahl, A., Nelson, R., Overturf, K., Rust, M., Sealey, W., Skonberg, D., Souza, E. J., Stone, D., Wilson, R., \& Wurtele, E. (2007). Expanding the utilization of sustainable plant products in aquafeeds: a review. Aquaculture Research, 38(6), 551-579. https://doi.org/10.1111/j.13652109.2007.01704.x

Hara, A., \& Radin, N. S. (1978). Lipid extraction of tissues with a low toxicity solvent. Analytical Biochemistry, 90(1), 420-426. https://doi.org/10.1016/0003-2697(78)900465
Henry, M., Gasco, L., Piccolo, G., \& Fountoulaki, E. (2015). Review on the use of insects in the diet of farmed fish: Past and future. Animal Feed Science and Technology, 203,

1-22. https://doi.org/10.1016/j.anifeedsci.2015.03.001

Howe, E. R., Simenstad, C.A., Toft, J.D., Cordell, J.R., Bollens, S.M.,. (2014). Macroinvertebrate prey availability and fish diet selectivity in relation to environmental variables in natural and restoring north San Francisco bay tidal marsh channels. San Francisco Estuary and Watershed Science, 12, 1-46.

Jabir, M. D. A., Razak, S. A., \& Vikineswary, S. (2012). Chemical composition and nutrient digestibility of super worm meal in red tilapia juvenile. Pakistan Veterinary Journal, 32(4), 489-493. <Go to ISI>://WOS:000310060000003

Jankowska, B., Zakes, Z., Zmijewski, T., \& Szczepkowski, M. (2010). Fatty acid profile of muscles, liver and mesenteric fat in wild and reared perch (Perca fluviatilis L.). Food Chemistry, 118(3), 764-768. https://doi.org/10.1016/j.foodchem.2009.05.055

Johri, R., Singh, R., Johri, P.K. (2010). Effect of different formulated plant and animal diet on hematology of Clarias batrachus Linn. Under laboratory conditions. Biochemical and Cellular Archives, 10, 283-291.

Kennedy, S. W., \& Jones, S. P. (1994). Simultaneous measurement of cytochrome p4501a catalytic activity and total protein-concentration with a fluorescence plate reader. Analytical Biochemistry, 222(1), 217-223. https://doi.org/10.1006/abio.1994.1476

Leung, D., Yang, D. P., Li, Z. X., Zhao, Z. M., Chen, J. P., \& Zhu, L. P. (2012). Biodiesel from Zophobas morio Larva Oil: Process Optimization and FAME Characterization. Industrial \& Engineering Chemistry Research, 51(2), 1036-1040. https://doi.org/10.1021/ie201403r

Li, Z. H., Zlabek, V., Velisek, J., Grabic, R., Machova, J., Kolarova, J., Li, P., \& Randak, T. (2011). Acute toxicity of carbamazepine to juvenile rainbow trout (Oncorhynchus mykiss): Effects on antioxidant responses, hematological parameters and hepatic EROD. Ecotoxicology and Environmental Safety, 74(3), 319-327. https://doi.org/10.1016/j.ecoenv.2010.09.008

Lund, E. K. (2013). Health benefits of seafood; Is it just the fatty acids? Food Chemistry, 140(3), 413-420. https://doi.org/10.1016/j.foodchem.2013.01.034

Manzano-Agugliaro, F., Sanchez-Muros, M. J., Barroso, F. G., Martinez-Sanchez, A., Rojo, S., \& Perez-Banon, C. (2012). Insects for biodiesel production. Renewable \& Sustainable Energy Reviews, 16(6), 3744-3753. https://doi.org/10.1016/j.rser.2012.03.017

Medale, F., Le Boucher, R., Dupont-Nivet, M., Quillet, E., Aubin, J., \& Panserat, S. (2013). Plant based diets for farmed fish. Inra Productions Animales, 26(4), 303-315. <Go to ISI>://WOS:000338001600001

Mraz, J., Schlechtriem, C., Olohan, L. A., Fang, Y. X., Cossins, A. R., Zlabek, V., Samuelsen, T., \& Pickova, J. (2010). Sesamin as a potential modulator of fatty acid composition in common carp (Cyprinus carpio). Aquaculture Research, 41(11), e851-e861. https://doi.org/10.1111/j.1365-2109.2010.02609.x

Ng, W. K., Liew, F. L., Ang, L. P., \& Wong, K. W. (2001). Potential of mealworm (Tenebrio molitor) as an alternative protein source in practical diets for African catfish, Clarias gariepinus. Aquaculture Research, 32, 273-280. https://doi.org/10.1046/j.1355-557x.2001.00024.x 
Ngoc, T. N., Pucher, J., Becker, K., \& Focken, U. (2016). Earthworm powder as an alternative protein source in diets for common carp (Cyprinus carpio L.). Aquaculture Research, 47(9), 2917-2927. https://doi.org/10.1111/are.12743

Nogales-Merida, S., Gobbi, P., Jozefiak, D., Mazurkiewicz, J., Dudek, K., Rawski, M., Kieronczyk, B., \& Jozefiak, A. (2018). Insect meals in fish nutrition. Reviews in Aquaculture, 1-14.

Ossey, Y. B., Koumi, A.R., Koffi, K.M., Atse, B.C., Kouame, L.P. (2012). Use of soybean, bovine brain and maggot as sources of dietary protein in larval Heterobranchus longifilis (Valenciennes, 1840). Journal of Animal and Plant Science, 15, 2099-2108.

Quartararo, N., Allan, G. L., \& Bell, J. D. (1998). Replacement of fish meal in diets for Australian snapper, Pagrus auratus. Aquaculture, 166(3-4), 279-295. https://doi.org/10.1016/s0044-8486(98)00289-0

Rawles, S. D., Riche, M., Gaylord, T. G., Webb, J., Freeman, D. W., \& Davis, M. (2006). Evaluation of poultry by-product meal in commercial diets for hybrid striped bass (Morone chrysops female $\times$ M.saxatilis male) in recirculated tank production. Aquaculture, 259(1-4), 377-389. https://doi.org/10.1016/j.aquaculture.2006.05.053

Riddick, E. W. (2013). Mass production of beneficial organisms. In J. A. Morales-Ramos, Shapiro-llan, D., Rojas, G.M. (Ed.), Insect protein as a partial replacement for fishmeal in the diets of juvenile fish and crustaceans: Invertebrates and entomopathogens. (pp. 565-582). Elsevier Science.

Rumpold, B. A., \& Schluter, O. K. (2013). Potential and challenges of insects as an innovative source for food and feed production. Innovative Food Science \& Emerging Technologies, 17, 1-11. https://doi.org/10.1016/j.ifset.2012.11.005

Russo, G. L. (2009). Dietary n-6 and $n-3$ polyunsaturated fatty acids: From biochemistry to clinical implications in cardiovascular prevention. Biochemical Pharmacology, $77(6)$, 937-946 https://doi.org/10.1016/j.bcp.2008.10.020

Schnaittacher, G., King, W., \& Berlinsky, D. L. (2005). The effects of feeding frequency on growth of juvenile Atlantic halibut, Hippoglossus hippoglossus L. Aquaculture Research, 36(4), 370-377. https://doi.org/10.1111/j.1365-2109.2005.01218.x

Simopoulos, A. P. (2002). The importance of the ratio of omega-6/omega-3 essential fatty acids. Biomedicine \&
Pharmacotherapy, 56(8), https://doi.org/10.1016/s0753-3322(02)00253-6

Smith, P. K., Krohn, R. I., Hermanson, G. T., Mallia, A. K., Gartner, F. H., Provenzano, M. D., Fujimoto, E. K., Goeke, N. M., Olson, B. J., \& Klenk, D. C. (1985). Measurement of protein using bicinchoninic acid. Analytical Biochemistry, 150(1), 76-85 https://doi.org/10.1016/0003-2697(85)90442-7

Taufek, N. M., Muin, H., Raji, A. A., Razak, S. A., Yusof, H. M., \& Alias, Z. (2016). Apparent digestibility coefficients and amino acid availability of cricket meal, Gryllus bimaculatus, and fishmeal in african catfish, Clarias gariepinus, diet. Journal of the World Aquaculture Society, 47(6), 798-805. https://doi.org/10.1111/jwas.12302

Thorpe, J. E. (1977). Morphology, physiology, behavior, and ecology of Perca fluviatilis L. and P. flavescens Mitchill. Journal of the Fisheries Research Board of Canada, 34, 1504-1514. https://doi.org/10.1139/f77-215

Trattner, S., Kamal-Eldin, A., Brannas, E., Moazzami, A., Zlabek, V., Larsson, P., Ruyter, B., Gjoen, T., \& Pickova, J. (2008). Sesamin Supplementation Increases White Muscle Docosahexaenoic Acid (DHA) Levels in Rainbow Trout (Oncorhynchus mykiss) Fed High Alpha-Linolenic Acid (ALA) Containing Vegetable Oil: Metabolic Actions. Lipids, 43(11), 989-997. https://doi.org/10.1007/s11745-008-3228-8

Turek, J., Sampels, S., Tilami, S. K., Červený, D., Kolarova, J., Randak, T., Mraz, J., Masilko, J., Steinbach, C., Burkina, V., Kozak, P., \& Zlabek, V. (2020). Insects in the feed of rainbow trout, Oncorhynchus mykiss (Actinopterygii, Salmonidae): Effect on growth, fatty acid composition, and sensory attributes. Acta Ichtyologica et Piscatoria, 50(2), 171-181.

van Huis, A. (2013). Potential of insects as food and feed in assuring food security. In M. R. Berenbaum (Ed.), Annual Review of Entomology, Vol 58 (Vol. 58, pp. 563-583). Annual Reviews. https://doi.org/10.1146/annurev-ento120811-153704

Xu, X. L., Fontaine, P., Melard, C., \& Kestemont, P. (2001). Effects of dietary fat levels on growth, feed efficiency and biochemical compositions of Eurasian perch Perca fluviatilis. Aquaculture International, 9(5), 437-449. https://doi.org/10.1023/a:1020597415669 